\title{
Characteristics of Bulgarian folk music
}

\section{Penka Pencheva Mincheva}

Faculty of Music Pedagogy, Academy of Music, Dance and Fine Arts - Plovdiv, Bulgaria, Europe

\section{Email address:}

pmincheva1935@abv.bg

\section{To cite this article:}

Penka Pencheva Mincheva. Characteristics of Bulgarian Folk Music. International Journal of Literature and Arts. Special Issue: Musical Theory, Psychology and Pedagogy. Vol. 2, No. 5-1, 2014, pp. 33-41. doi: 10.11648/j.ijla.s.2014020501.16

\begin{abstract}
This paper presents the unique richness and diversity of the Bulgarian folk music. It discusses its modal specificity - the widespread use of old modal structures and chromatic sound lines, the metrorhytmical diversity; indicates some features such as the non-measured song. The most commonly used modal structures and the most widespread metrums are highlighted. A special focus is the successional bond of the native folklore and the professional Bulgarian musical works.
\end{abstract}

Keywords: Bulgarian Folk Music, Monodic and Harmonic Mode Structures, Irregular Meters, Non-Measured Song

\section{Introduction}

Bulgaria is situated in the middle of the Balkan Peninsula - in the Southeastern part of Europe. Being a kind of "a crossroad" between Europe, Asia and Africa determines its status of a country having been inhabited by many different peoples in the course of the years. Many historical artifacts have been found from the Thracian, Greek and Roman civilizations. The state of Bulgaria, a heir to numerous ancient cultures, appeared on the map more than one thousand three hundred years ago. It is known that the second largest city in the country - Plovdiv - is the fifth among the oldest cities in the world. For five centuries of its millennial history - from the fourteenth to the nineteenth century - Bulgaria was under Ottoman rule. During this period, the Bulgarians have lived in small isolated villages, but have never accepted the foreign influence. This position is supported by the fact that our people have preserved their ethnic identity despite their oppressors' attempts for a forced assimilation. This has become possible thanks to our language, literature, religion (Eastern Orthodox Christianity) and folklore - traditions, rituals, songs and dances, stories, legends and humor. That is precisely the reason why we claim that Bulgarian folk music is distinctive, original, with deep historical roots and preserved for the generations.

\section{Subject, Purpose and Objectives of the Study}

The object of the present study is the Bulgarian musical folklore.

The subject of this study is the modal and the metrorhytmic variety of the Bulgarian folk music.

The main purpose is the summarized presentation to the world of the immense diversity and originality of the vocal and the instrumental works of the nameless folk musicians, highlighting the most commonly used modal structures, methrums and rhythmic groups and tracing the successional bond of the native musical folklore with the Bulgarian professional musical works.

Since the melody - the basis of the vocal folk art - is a sequence of sounds of different heights and durations, the specific tasks to be explored are:

2.1. Outlining the specifics of the modes in Bulgarian vocal folk art, since the mode is the organizer of the tones in the melody in a logical musical thought.

2.2. Highlighting the most common modal structures;

2.3. Deducing the metrorhythmic features of the Bulgarian folk songs, since thanks to the meter and the rhythm the temporal characteristics of the melody are achieved;

2.4. Identifying the most common metric pulsations and rhythmic groups;

2.5. Revealing the application of the Bulgarian folk musical works in the professional music.

For the sake of clarity the features of the mode, as well as those of meter and rhythm, typical for the Bulgarian folk melodies, have to be analyzed separately. 


\section{Structure of the Modes of the Bulgarian Folk Songs}

The components of the mode are the mode structures and the mode functions [1].

\subsection{Mode Structures}

Mode structures are the tones that build the melody, arranged by their height. There are two large groups of mode structures:

\subsubsection{Monodic Mode Structures}

They are an earlier form of musical thought. Their origin is associated with the freely narrated monophonic vocal music thought. Since it "illustrates" a verbal text, following the emotional content of the narration, it uses a large variety of means of expression, i.e. sound sequences which differ in volume (number of scale's degrees) and in interval structure (height ratios between the scale's pitches).

\subsubsection{Harmonic Mode Structures}

They appear with the development of the music, performed in multiple voices - two, three or more. Due to the need of coordination of the simultaneous sounding of several different pitch heights, the main mean of expression in this case is the assonance - the chord. This requires the use of tone rows strictly regulated in volume and in interval construction - the heptatonic classic major and minor and their variants - harmonic and melodic major and minor.

Thus, the leading aspect in the functioning of the monodic mode structures is the horizontal, while in the harmonic ones - the vertical.

\subsection{Mode Functions}

The mode functions are the second important component of the mode. In the course of the centuries-old history of music art two main types of functions between the tones of the melody have differentiated: anchoring - not anchoring and stability - instability [1].

\subsection{1. "Anchoring - Not Anchoring" Functions}

These functions are observed in the monodic mode structures. An anchor tone in the melody is the one which:

- Appears at the end of the musical thought, i.e. resonates in the mind of the singer and the listener.

- Has a longer duration.

- The tone which has sound at the end of a separate music fragment also leaves the impression of "anchoring". In a particular mode structure the anchoring function is not regulated in advance.

This means that each tone in the melody may acquire the anchoring function, provided the above mentioned conditions are fulfilled.

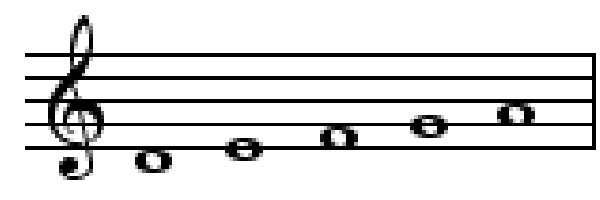

Figure 1a. A tone row.

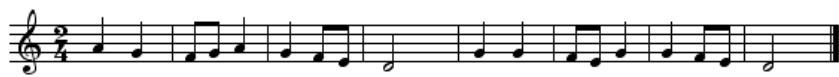

Figure 1b. Round Dance - a folk melody. The final, and thus anchoring tone, is the lowest one.

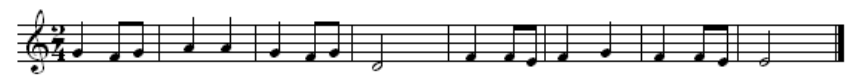

Figure 1c. Round Dance - a folk melody. The final tone is the second degree in the tone row.

Tone rows with different number of degrees are used in Bulgarian music folklore - some of them consist of only two degrees, others of three, four, etc, while there are such which surpass an octave. The tone rows used differ in their interval structure as well. For example, a tone row of four degrees ,c $-\mathrm{d}-\mathrm{e}-\mathrm{f}$ ' can be found in the following variants:

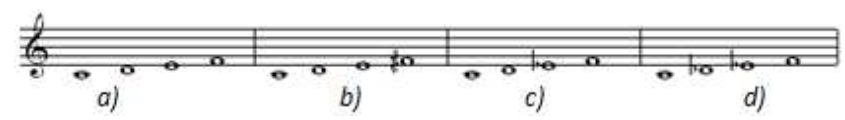

Figure 2. Variants of a tone row of four degrees, used in Bulgarian folk music.

The greater the number of degrees in the tone row is, the more various its structure is.

Songs written in medieval mode structures have a big share in Bulgarian music folklore. Most of them are in Aeolian mode, followed by the songs in Phrygian mode (Figure 3), in Ionic mode (Figure 4). Quite a few is also the number of the songs in a Mixolydian mode (Figure 5). The Doric mode occurs as well, though being rarely included. The great variety of mode structures even includes tone rows, such as the pentatonic (Figure 6).

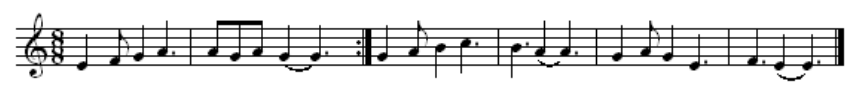

Figure 3. "A Girl" - Bulgarian folk song in Phrygian mode.
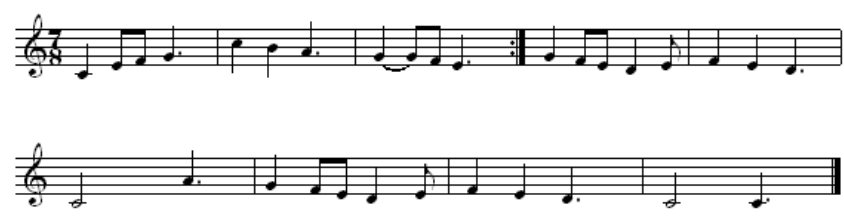

Figure 4. "A Small Belt" - Bulgarian folk song in Ionic mode.
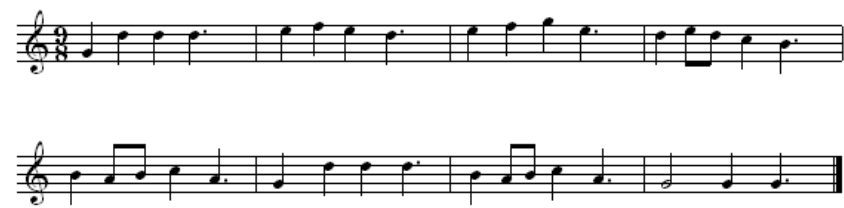

Figure 5. "White Rada" - Bulgarian folk song in Mixolydian mode. 

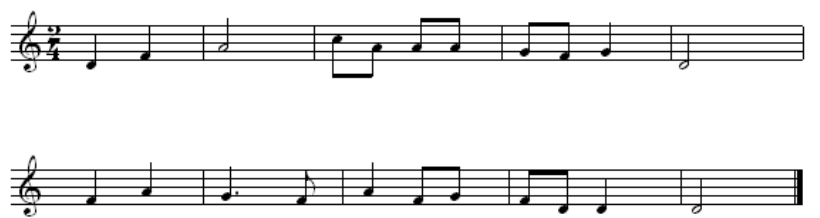

Figure 6. "I Have Been Begging You" - Bulgarian folk song in minor pentatonic.

The prominent Bulgarian scientist and ethnomusicologist, Prof. Stoyan Dzhudzhev, introduces another classification of the modes - diatonic and chromatic. Diatonic are the structures built of major and minor seconds (semitone and whole-tone intervals between the neighboring pitch levels) - the medieval modes also belong to that group. In the chromatic mode structures there is the augmented second included (a tone and a half interval - a hiatus - Figures $7 \mathrm{a}$ and $7 \mathrm{~b}$ ). These tone rows are very largely included in Bulgarian folk music. In tone rows which surpass an octave another interesting phenomenon occurs - a tone in the melody and its "octave" repetition do not form a perfect octave:
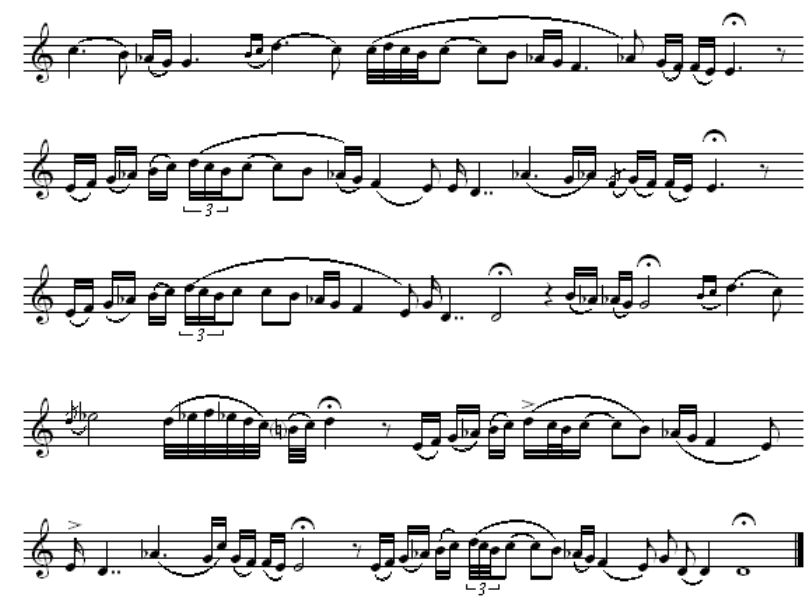

Figure 7a. "Grozdanka" - Bulgarian folk song.

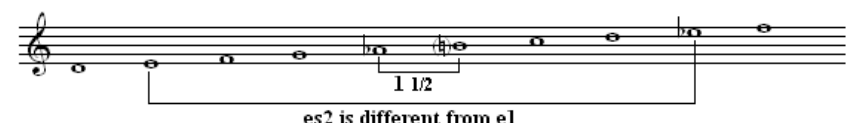

Figure $7 \boldsymbol{b}$. A tone row of the folk song "Grozdanka". An augmented second is formed between the tones as and $h^{l}$, while the tone $e^{l}$ sounds in the second octave like es ${ }^{2}$

Another interesting point is the so-called "melodic modulation" [1]. Within it the separate fragments of the song develop in tone rows, different in volume and structure:

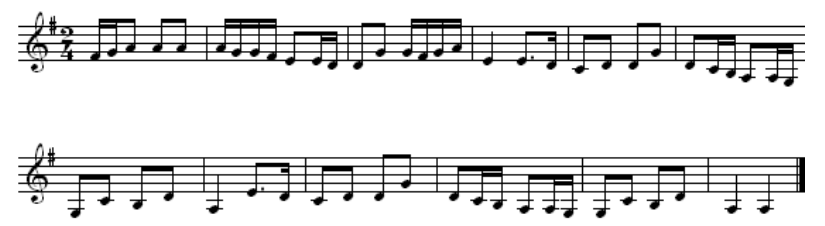

Figure 8a. "I Am Glad To" - Bulgarian folk song. A melodic modulation in which the two song fragments are developed in mode structures, different in volume.

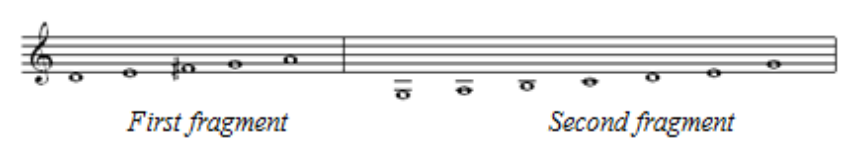

Figure $8 \boldsymbol{b}$. Mode structures of the two fragments of the same folk song.
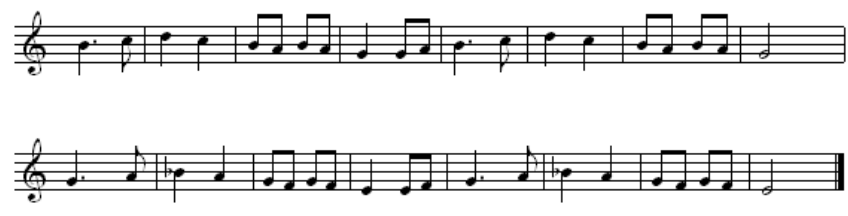

Figure 9a. "You, Violet" - Bulgarian folk song. The melodic modulation, in which the two fragments of the song develop in mode structures, different in their interval structures.

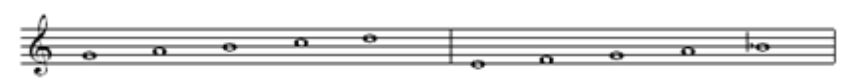

\section{First fragment Second fragment}

Figure $9 b$. Mode structures of the two fragments of the same folk song

The given examples present the Bulgarian folk song as a clearly distinguishable one, very bright and original, regarding its intonation nature, caused by its diverse mode structure.

\section{A texture of Multiple Voices}

The largest part of Bulgarian folk songs is of monophonic texture, but in two particular regions it is a common practice for another voice to sound under the main melody. This second voice is different for the Pirin Folklore Region and the Shopluka Folklore region.

\subsection{Ison or Bourdon Biphonic Texture}

It is typical for the Pirin Folklore Region. In it the lower voice is performed on one and the same tone.

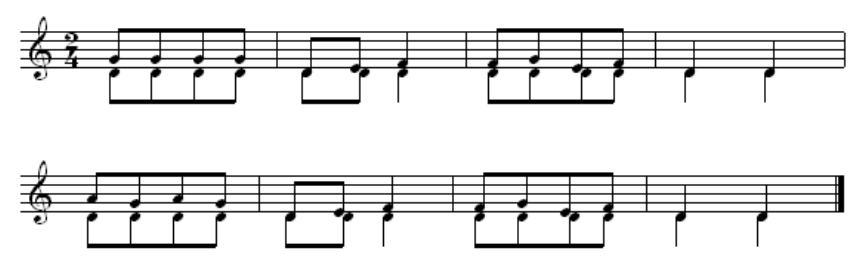

Figure 10. "Dzhore" - Bulgarian folk song.

\subsection{True Biphonic Texture}

It is typical for the Shopluka Folklore Region. The lower voice follows the high one, often in intervals of a second. The sounding is sharp.

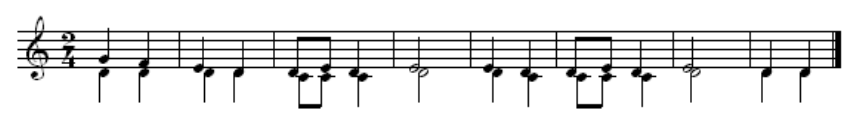

Figure 11. "Geranium, Wreath" - Bulgarian folk song. 

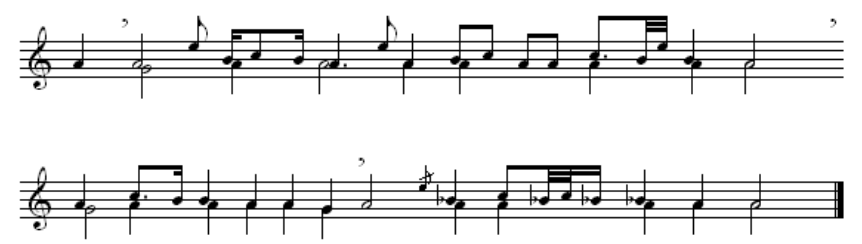

Figure 12. "Still Sun" - Bulgarian folk song.

As evident from the given examples, Bulgarian folk polyphonic singing also sounds unusual, original and its dissonances give it certain special, inimitable energy and vitality.

\section{Specifics of Meter and Rhythm of the Bulgarian Folk Songs}

For reasons of clarity of exposition it is therefore necessary to specify the terms used to refer to the elements of the organized flow of tones in the melody in the course of time.

The tones, different in duration, compose the rhythm, whose perception is facilitated by its metric fragmentation. The meter organizes the rhythm through the strong and the weak pulses - metric beats.

\subsection{Metric Diversity}

Two basic metric forms are used in music - the duple and the triple.

A substantial part of the songs in Bulgarian music folklore are performed in very quick tempos, which does not allow the measuring of each of the metric beats. This requires the grouping of the primary metric beats (Table 1) into units, so that the timing can be done by groups of metric beats. According to the types of units (duple or triple), combined in the meter of the particular song, another two categories of meter can be classified: regular - built of only duple or triple units; and irregular (changing) - built of both duple and triple units. The vast variety of meters is one of the most typical characteristic features of Bulgarian folk music. Some irregular meters can be found in the folk music of other countries in the region - Macedonia, Serbia, Greece, Turkey, but never in such a variety as in the Bulgarian folklore. I will give the following example: $a_{8}^{5}$ time signature, in which we have two different units - a duple and a triple, can be found in the neighboring countries in two variants:

Table 1. Basic metric types

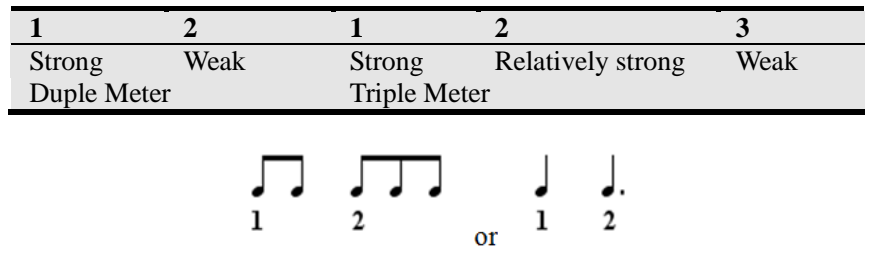

Figure 13. Variants of ${ }_{8}^{5}$ time signature, popular in the Balkan Peninsula.
In Bulgarian folk songs, however, though less frequently, the following version is used as well:

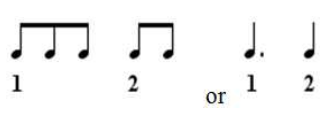

Figure 14. A version of ${ }_{8}^{5}$ time signature, popular in Bulgaria.

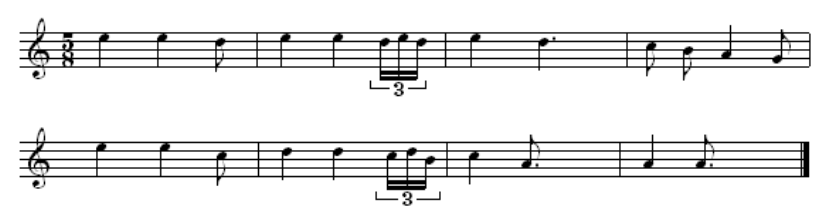

Figure 15. "In the Garden" - Bulgarian folk song

The most frequent tripartite ${ }_{8}^{7}$ time signature is:

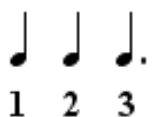

Figure 16a. The most popular variant of the tripartite ${ }_{8}^{7}$ time signature.

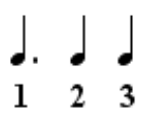

Figure 16b. A less used variant of the tripartite ${ }_{8}^{7}$ time signature.

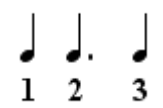

Figure 16c. The least used variant of the tripartite ${ }_{8}^{7}$ time signature.

The ${ }_{8}^{8}$ irregular time signature is also a tripartite one. It can be found in the following variants:

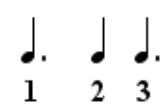

Figure 17a. The most popular variant of the tripartite ${ }_{8}^{8}$ time signature

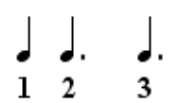

Figure 17b. A less used variant of the tripartite ${ }_{8}^{8}$ time signature.

$$
\begin{array}{lll}
\text { d. } & \text { d. } & \text { d } \\
1 & 2 & 3
\end{array}
$$

Figure 17c. The least used variant of the tripartite ${ }_{8}^{8}$ time signature.

I have to point out the well-developed ability of the Bulgarians for accurate and precise interpretation of the meter and the rhythm together - when folk singers perform the songs one can clearly detect the small but significant difference between the ${ }_{8}^{7}$ time signature, as shown on Figure $16 \mathrm{~b}$, and the ${ }_{8}^{8}$ signature, as given on Figure $17 \mathrm{a}$ : 


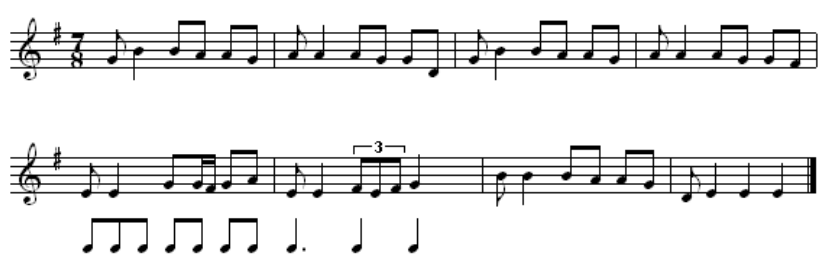

Figure 18. "White Rada" - Bulgarian folk song, ${ }^{7}$ time signature with a starting triple unit and primary metric beats and units, given below the score.

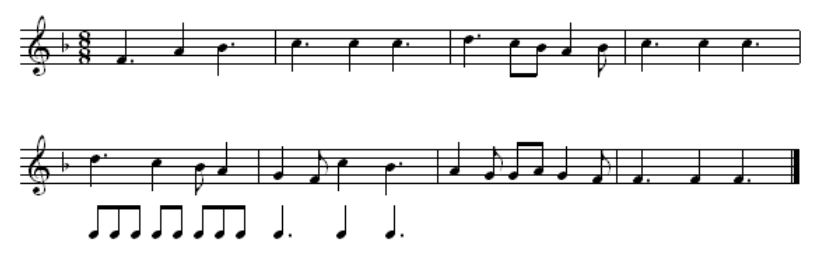

Figure 19. "What is My Dear" - Bulgarian folk song, ${ }_{8}^{8}$ time signature with triple units on position 1 and 3 and primary metric beats and units, given below the score.

Besides the examples shown above, other irregular meters can be found in Bulgarian music folklore $-{ }_{8}^{9}$ time signature of four units in the following variants: with a triple unit at the end (Figure 20a); with a triple unit in the second place (Figure 20b); and the less popular variants - with a triple unit in the first place (Figure 20c) and with a triple unit in the third place (Figure 20d).

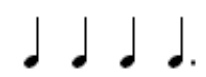

Figure 20a. ${ }^{9}$ time signature of four units with a triple unit at the end.

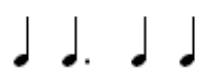

Figure 20b. ${ }_{8}^{9}$ time signature of four units with a triple unit in the second place.

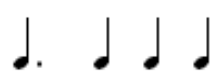

Figure 20c. ${ }_{8}^{9}$ time signature of four units with a triple unit in the first place.

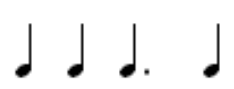

Figure 20d. ${ }_{8}^{9}$ time signature of four units with a triple unit in the third place.

The ${ }_{8}^{10}$ irregular time signature, composed of four units, can be found in several variants as well: with triple units in the first and the fourth place (Figure 21a) - the most used one; with triple units in the third and the fourth place (Figure 21b) - also popular; with triple units in the first and the second place (Figure 21c) - less popular; and with triple units in the second and the third place (Figure 21d) - only on rare occasions.

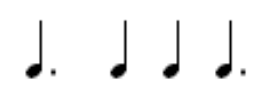

Figure 21a. ${ }^{10}$ sirregular time signature of four units with triple units in the first and the fourth place.

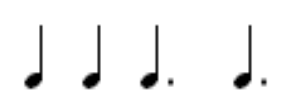

Figure 21b. ${ }^{10}{ }_{8}$ irregular time signature of four units with triple units in the third and the fourth place.

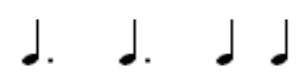

Figure 21c. ${ }^{10}{ }_{8}$ irregular time signature of four units with triple units in the first and the second place.

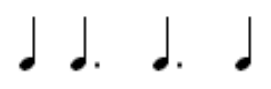

Figure 21d. ${ }^{10}{ }_{8}$ irregular time signature of four units with triple units in the second and the third place.

The ${ }_{8}^{11}$ irregular time signature, composed of four units, can be found in the following variant:

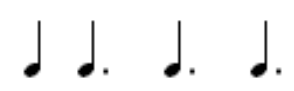

Figure 22a. ${ }^{11}{ }_{8}$ irregular time signature of four units with triple units in the second, the third and the fourth place.

The other variants of this time signature are very rare.

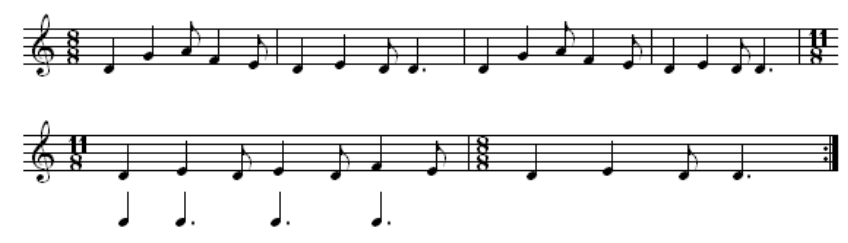

Figure 22b. "Dilmano, Dilbero" - Bulgarian folk song. ${ }_{8}^{8}$ irregular time signature with triple units in the second and the third place and ${ }^{11}{ }_{8}$ irregular time signature of four units, with triple units in the second, the third and the fourth place.

The ${ }_{8}^{11}$ irregular time signature of five units can be found in the following variants:

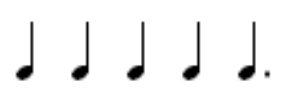

Figure 23a. ${ }^{11}{ }_{8}$ irregular time signature of five units with a triple unit in the fifth (the last) place.

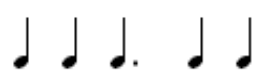

Figure 23b. ${ }^{11}$ sirregular time signature of five units with a triple unit in the third place.

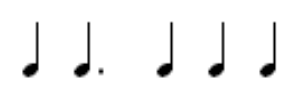

Figure 22c. ${ }^{\text {ll }}{ }_{8}$ irregular time signature of five units with a triple unit in the second place.

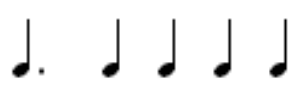

Figure 22d. ${ }^{11}{ }_{8}$ irregular time signature of five units with a triple unit in the first place. 


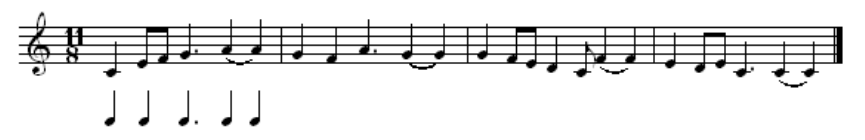

Figure 24a. "When My Mother..." - Bulgarian folk song. ${ }^{11}{ }_{8}$ irregular time signature of five units with a triple unit in the third place

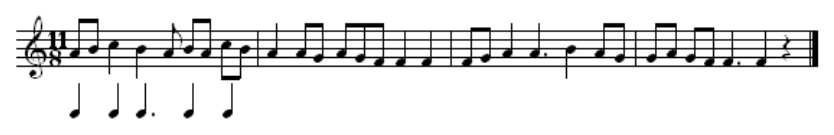

Figure 24b "A Curved Ring Dance" - Bulgarian folk song. ${ }^{11}$ sirregular time signature of five units with a triple unit in the third place.

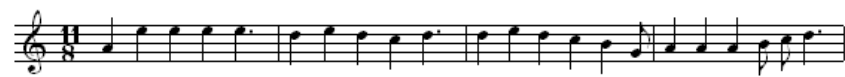

Figure 25. "Sitting On a Chair" - Bulgarian folk song. ${ }^{11}{ }_{8}$ irregular time signature of five units with a triple unit in the fifth place.

The ${ }_{8}^{12}$ irregular time signature can be found in a composition of five units, two of which triple and three duple.

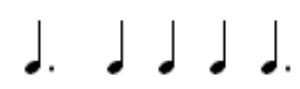

Figure 26a. ${ }^{12}{ }_{8}$ irregular time signature of five units with triple units in the first and the fifth place.

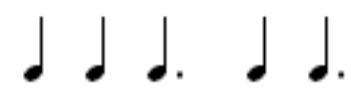

Figure 26b. ${ }^{12}$ irregular time signature of five units with triple units in the third and the fifth place.

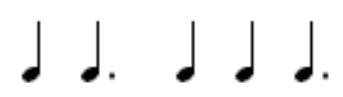

Figure 25c. ${ }^{12}$ sirregular time signature of five units with triple units in the second and the fifth place.

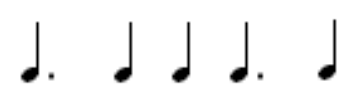

Figure 26d. ${ }^{12}{ }_{8}$ irregular time signature of five units with triple units in the first and the fourth place.

The ${ }_{8}^{13}$ irregular time signature can be found in a composition of five units, two of which duple and three triple. It is also popular in a composition of six units, five of which duple and one - triple. The most common configurations of the two duple and the three triple units in a ${ }_{8}^{13}$ irregular time signature of five units are:

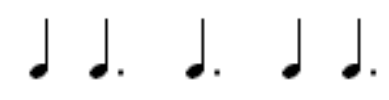

Figure 27a. ${ }^{13}{ }_{8}$ irregular time signature of five units with triple units in the second, the third and the fifth place.

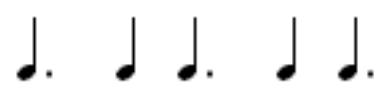

Figure 27b. ${ }^{13}$ sirregular time signature of five units with triple units in the first, the third and the fifth place.
Following are the variants of the ${ }_{8}^{13}$ irregular time signature in a composition of six units:

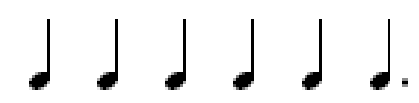

Figure 28a. ${ }^{13}{ }_{8}$ irregular time signature of six units with a triple unit in the sixth place.

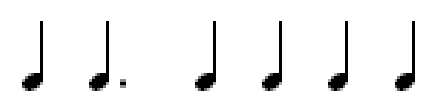

Figure 28b. ${ }^{13}{ }_{8}$ irregular time signature of six units with a triple unit in the second place.

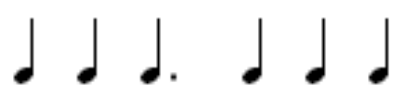

Figure 28c. ${ }^{13}{ }_{8}$ irregular time signature of six units with a triple unit in the third place.

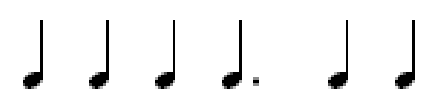

Figure 28d. ${ }^{13}{ }_{8}$ irregular time signature of six units with a triple unit in the fourth place.

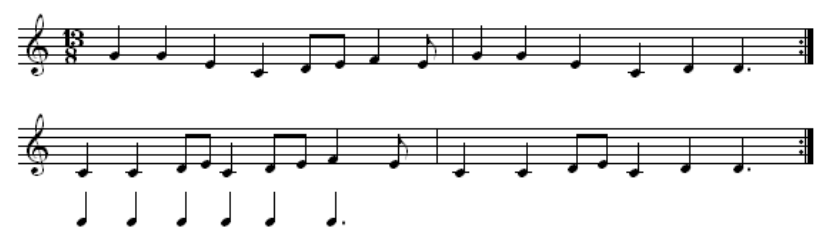

Figure 29. "Tsone, My Dear Child" - Bulgarian folk song. ${ }^{13}$ irregular time signature of six units with a triple unit in the sixth place.

The ${ }_{8}^{14}$ time signature is composed of six units, four of them duple and two - triple:

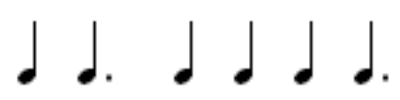

Figure 30a. ${ }^{14}$ irregular time signature of six units with triple units in the second and the sixth place.

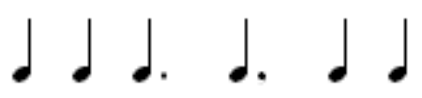

Figure 30b. ${ }^{14}{ }_{8}$ irregular time signature of six units with triple units in the third and the fourth place.

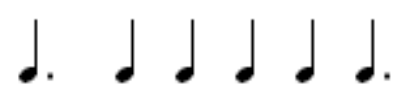

Figure 30c. ${ }^{14}{ }_{8}$ irregular time signature of six units with triple units in the first and the sixth place.

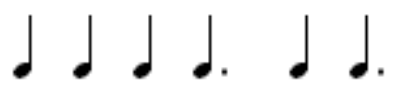

Figure 30d. ${ }^{14}{ }_{8}$ irregular time signature of six units with triple units in the fourth and the sixth place.

The songs in ${ }_{8}^{14}$, listed below, are popular and frequently 
performed:

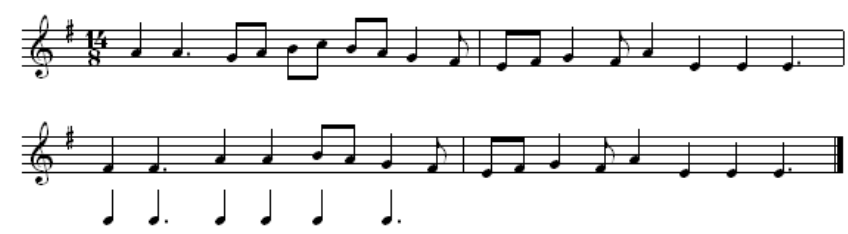

Figure 31a. "Mommy, Tell My Daddy" - Bulgarian folk song. ${ }^{14}{ }_{8}$ irregular time signature of six units with triple units in the second and the sixth place.
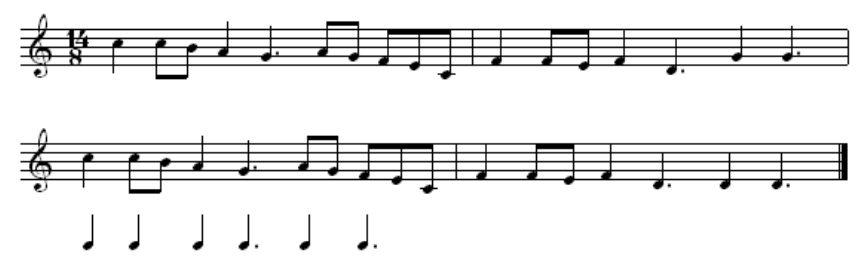

Figure 31b. "Go Ahead, My Horse" - Bulgarian folk song. ${ }^{14}$ irregular time signature of six units with triple units in the fourth and the sixth place.

The ${ }_{8}^{15}$ time signature is composed of six units, three of which duple and three - triple. The used variants are:

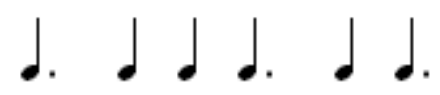

Figure 32a. ${ }^{15}{ }_{8}$ irregular time signature of six units with triple units in the first, the fourth and the sixth place.

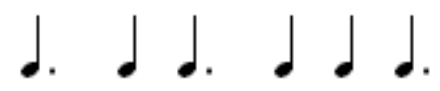

Figure 32b. ${ }^{15}{ }_{8}$ irregular time signature of six units with triple units in the first, the third and the sixth place.

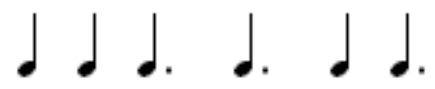

Figure 32c. ${ }^{15}{ }_{8}$ irregular time signature of six units with triple units in the third, the fourth and the sixth place.

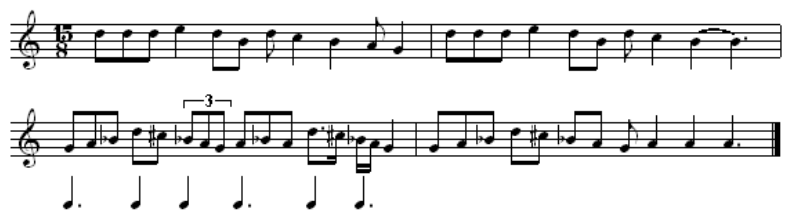

Figure 33a. "Nine Years"-Bulgarian folk song. ${ }^{15}{ }_{8}$ irregular time signature of six units with triple units in the first, the fourth and the sixth place.
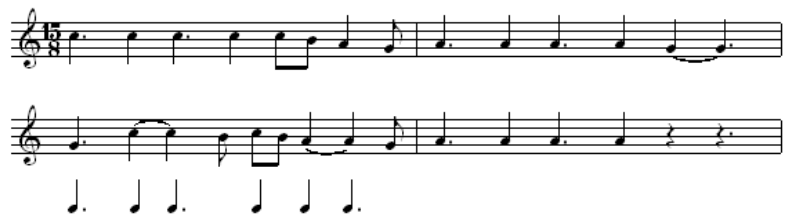

Figure 33b. "Radka, Mother's Child" - Bulgarian folk song. ${ }^{15}$ irregular time signature of six units with triple units in the first, the third and the sixth place.

The time signature can be found in a composition of seven units, six of which duple and one triple:

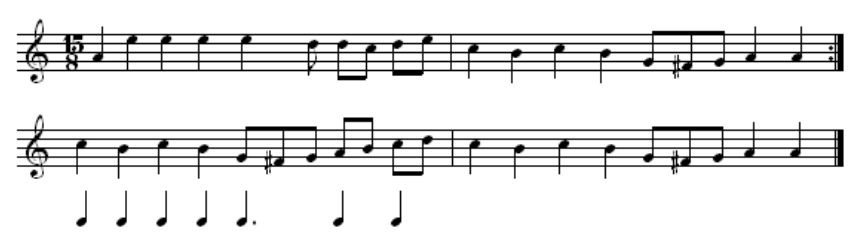

Figure 34 "A Round Dance" - Bulgarian folk song. ${ }_{8}^{15}$ irregular time signature of seven units with a triple unit in the fifth place.

The presented configuration variants of the duple to the triple units do not cover all the metric diversity of Bulgarian folk music. The figures above show the most popular ones only.

\subsection{Rhythmic Diversity}

Besides the diversity of metric forms, Bulgarian folk music is rich in rhythms, too. For example, the duple rhythmic group can be found in the following forms:

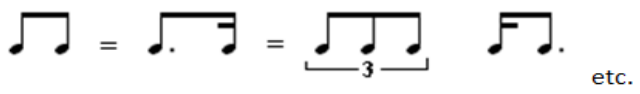

Figure 35. Examples of how the duple rhythmic group is diversified.

The triple rhythmic group can be found in the following forms:

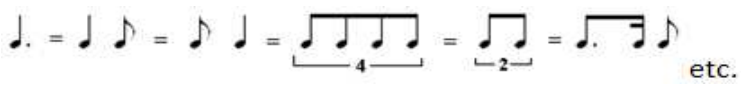

Figure 36. Examples of how the triple rhythmic group is diversified.

\subsection{Non-Measured Folk Songs}

A large number of songs don't have their meter organized - these are the so-called non-measured songs (Figure 7a, Figure 37). Usually such songs are performed in a slow tempo. They have a loose and free sounding, and when noted - the note values are symbolic and approximate.

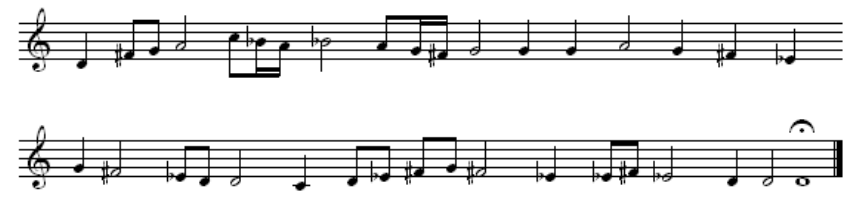

Figure 37. "Sleep..." - Bulgarian non-measured folk song.

\section{Bulgarian Folk Songs in the Professional Art of Music}

The Bulgarian treasury of songs has inspired many national artists in music. In "A Rhythmic Motion" - a piano piece by Pancho Vladigerov - one of the leading Bulgarian composers of the mid-twentieth century - three of the discussed features of the Bulgarian folk music can be found: the chromatic tone row determines the originality of intonation of the musical language (Figure 37), the layering of harmonic seconds in the accompaniment of chords directs to the typical diaphony of our folk songs, while the 
meter and the rhythm is recreated in an original manner, especially in the combination of two of the variants of ${ }^{9} 8$ time signature - regular of 3 units and irregular of 4 units (Figure 39a, Figure 39b). The theme of the piece is:
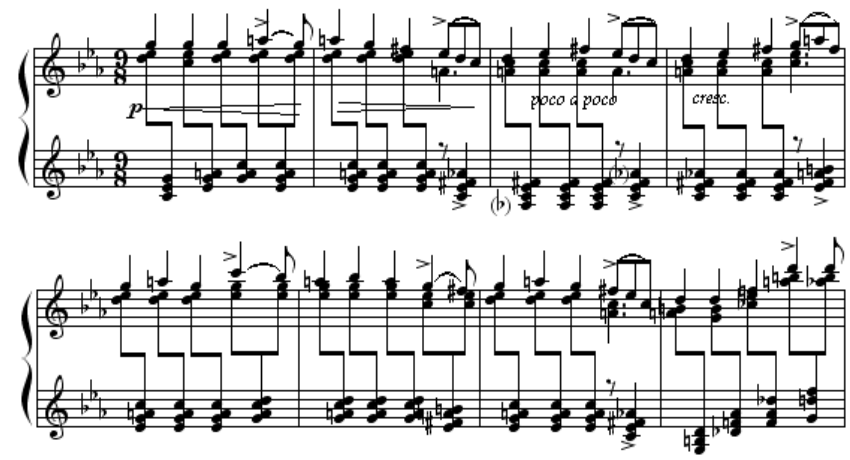

Figure 38. Pancho Vladigerov - "A Rhythmic Motion", theme (b. 13 - 20).

In the course of the development of the thematic material a phenomenon between the two hands occurs, i.e. the so-called "polymeter":

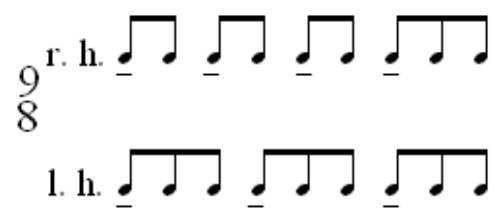

Figure 39a. Metric organization of some fragments of the middle section of "A Rhythmic Motion" by Pancho Vladigerov.

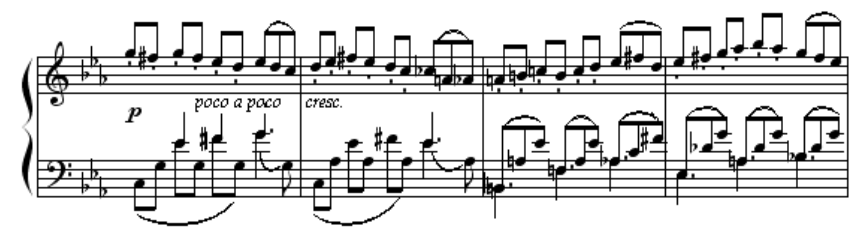

Figure 39b. Pancho Vladigerov - "A Rhythmic Motion", b. 49-52

This technique of simultaneous sounding of a regular and irregular meter with an equal number of metric beats, was later used by the Bulgarian jazz composer Milcho Leviev, who works in the United States.
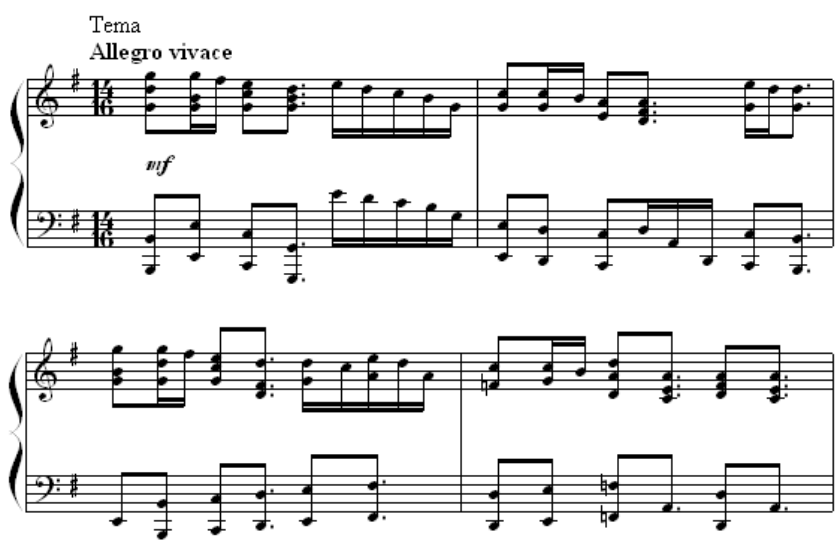

Figure 40. Lyubomir Pipkov - "Two Rhythmic Variations ", theme (b. 1 4)
The folk song "Go Ahead, My Horse", mentioned above (Figure 31b), has served as an inspiration to the eminent composer Lyubomir Pipkov in his piano piece "Two Rhythmic Variations" (Figure 40).

\section{Conclusions}

7.1. In the Bulgarian musical folklore the medieval modes are widely used; of them the most widespread is the Aeolian, followed by the Phrygian and the Ionian mode. The Doric mode is rare.

7.2. In the Bulgarian folk music are well represented also the chromatic modal structures, which include an augmented second.

7.3. In the Bulgarian national musical art are found modal structures, such as pentatonic, too, which is especially characteristic of the Rhodope region.

7.4. In the Bulgarian musical folklore are very commonly used irregular metrums. Among the most common irregular metrums are ${ }_{8}^{7}$ - in the versions with a three-beat group in the third place and also with a three- beat group in the first place; ${ }_{8}^{9}$ with a threebeat group in the fourth place and a three- beat group in the second place; ${ }_{8}^{5}$ in both versions - with a threebeat group in the second place and a three- beat group at the beginning; ${ }_{8}^{8}$ (irregular) with a three- beat group at the beginning and at the end. From ${ }_{8}^{10}$ to ${ }_{8}^{15}$ are found different variants of alternating two- beat and three- beat groups.

7.5. A typical phenomenon in the Bulgarian musical folk art is the non-measured melody, which has no metric pulsation and the rhythmic ratios are approximately fulfilled.

7.6. The native musical folklore is a rich and stable basis for the deployment of the Bulgarian professional musical works.

Bulgarian composers recreate the characteristic features of Bulgarian music folklore, thus renewing the world's treasury of music. We, the ordinary musicians, take pride in our national music culture. To the foreigners, who discover the Bulgarian folk song, we wish a lot of joyful emotions with it.

\section{References}

[1] Bershadskaya, T. Lectures On Harmony. Leningrad, 1978 (Бершадская, Т. Лекции по гармонии. Ленинград, 1978)

[2] Dzhudzhev, St. Bulgarian Music, Volume 1, Rhythm. Sofia, 1970 (Джуджев, Ст. Българска музика, том 1 Ритъм. София, 1970)

[3] Dzhudzhev, St. Bulgarian Music, Volume 2, Melody. Sofia, 1975 (Джуджев, Ст. Българска музика, том 2 Мелодика. София, 1975)

[4] Mincheva, P. Education Of Musical Hearing With The Means of Bulgarian Music Folklore. Sofia, 1985 (Минчева, П. Възпитание на музикалния слух чрез българския музикален фолклор. София, 1985) 
[5] Mincheva, P. Music Education In The General Education Schools. Sofia, 1994 (Минчева, П. Музикалното възпитание в общообразователното училище. София, 1994) 